\title{
THE EFFECT OF USING DISCUSSION BOARDS ON EFL WRITING CLASSES: AN ACTION RESEARCH CASE STUDY
}

\author{
${ }^{1}$ Saaed A. Saaed, ${ }^{2}$ Aveen A. Mohammed \\ ${ }^{1}$ Department of English, Collage of Languages, University of Duhok, Kurdistan Region, Iraq \\ ${ }^{2}$ Department of English, College of Basic Education, University of Duhok, Kurdistan Region, Iraq
}

\begin{abstract}
Online discussion boards (henceforth DBs) are nowadays widely implemented to guarantee better learning outcomes. DBs are considered a teaching method that provides more opportunities to learn a new language beyond time and physical constraints. This study was conducted to investigate the effect of the use of DBs on EFL students' learning, particularly their achievement in academic writing. The study was carried out in the department of English, College of Basic Education, University of Duhok, Kurdistan Region of Iraq. The sample of this study involved a total number of 56 male and female undergraduate students divided into two groups, the experimental group involved 28 students and the control group involved 28 students. The experimental group students were enrolled in a blended course to learn academic writing. The students involved were taught using both modes, online DBs and faceto-face sessions. The results indicated that students in the experimental group showed a better degree of improvement in exam scores than those in the control group. The findings showed that the implementation of DBs in addition to face-to face-classes in teaching English is likely to lead students to better achievement.
\end{abstract}

Keywords: blended learning, discussion boards, face-to-face classes, writing skills, better achievement.

\section{Introduction}

Discussion boards/forums are generally defined as an ICT tool which enables users to communicate, discuss and share their views online independent of time and place. DBs have been used for teaching purposes in multiple fields such as economy, biology, medicine and language teaching in recent years with the rapid innovation of technology. It allows teachers to communicate with their students beyond physical classroom via sharing lessons materials and creating discussion venues to extend face-to-face discussion.

Chen (2005, p.3) has found that DBs environment provides "time-place independence interactive writing space where learners can ponder and compose messages at their own pace and they can also produce either monologue- or conversation-like forms of written messages for reflective and communicative practice".
The increased popularity of DBs in language teaching sector has amplified the number of studies and research focusing on the effectiveness of using such tools on students satisfaction, achievement, developing higher order thinking and problem-solving skills.DBs create a bridge between the face-to-face class and online setting as the teacher creates a forum and invites students to discuss, comment and share their views online.

For these reasons, this study investigates whether DBs can contribute in developing students' achievement in academic writing classes. The study evaluates the role of DBs in supporting face-to-face classes in University of Duhok context, College of Basic Education.

\subsection{The hypothesis of the study}

Involving students in DBs can lead to higher achievement in writing. 


\subsection{Research questions}

Does involving students in DBs develop their writing?

\subsection{The Aim of the study}

As stated earlier, with the rapid innovation of technology, attempts are made to utilize ICT tools in teaching process. As a result, the interest to implement DBs in EFL writing classes around the world has arisen. As a researcher and a future teacher, I believe that such a tool has the potential to support EFL students to develop their writing skills. The study aims at investigating the role of DBs in improving achievement in writing.

ICT, in general, may have significant potential to foster English language teaching and learning especially in the writing domain in EFL classes. Using its simplest implementations, the online DBs may affect the teaching of writing as a skill using another new context can be beneficial. On the other hand, using DB s may have some challenges.

Although there is a lot of studies around the world on the use of DBs in EFL teaching domain, there are not many studies about the use of DBs in Kurdistan region of Iraq. Therefore, this study which aims at analyzing the role of DBs in EFL writing classes in University of Duhok ,is the sole one to be carried out.

\subsection{Limitation of the study}

There are certain limitations to this study: first it involved a relatively small population of second stage EFL students $(n=56)$ in writing classes. Second, students' development in writing was measured over only a one-term course. The other students who do not belong to the second stage students are not within the scope of this research. This study does not cover the effect of DBs on other skills such as reading, speaking, and listening skills.

\subsection{The significance of the study}

ICT, in general, may have a significant potential to foster
English language teaching and learning especially in the writing sector in EFL classes. Using its simplest implementations, the online DBs may affect the teaching of writing as a skill using another new context. Although there is a lot of studies around the world concerned with the use of DBs in EFL teaching domain, there are not many studies about the use of DBs in the Kurdistan region of Iraq. Therefore, this study may contribute to the teaching of English domain by using DBs in writing classes for the first time.

\section{Literature Review}

Before the emergence of technology and involvement of computers and mobile phones in learning context, evidence of using blended learning approach can be traced back to the $19^{\text {th }}$ century. Pappas (2015) claims that Sir Isaac Pitman was the first who merged two kinds of learning strategies. Pitman used to send his students materials and homework via mailed postcards and required them to send them back to be graded and corrected. As technology evolved in the 80s and 90s, schools and universities in the western world started to make use of its tools to enhance interaction between their students and stakeholders which was believed eventually to achieve better learning outcomes. In 2000 till today higher education environment have tried to create union between the traditional face-to-face classes and online-based learning by implementing various aspects of technology into traditional learning.

Blended learning has lastly appeared in language teaching and learning area however, Whittaker (2013) stated that it is difficult to trace back when it was exactly employed. Yet, Whitaker (2013) believed it coincided with the publication of Sharma and Barrett's book Blended Learning in 2007.Nonetheless, Ramasubbu (2015) claimed that the term blended learning has been introduced as early as 2000 .

Literature on blended learning documents that there is 
no specific definition for it .Some researchers simply define blended learning as a combination of both faceto-face and online learning environments.

Previous literature has shown that technology-enhanced classes in language teaching are advocated for many reasons such as boosting motivation, developing higher thinking order, creating collaborative environment and improving language skills. However ,studies such as Salehi and Salehi (2012), Riasati , Allahyar and Tan (2012) and Raman and Yamat (2014) have reported several difficulties and barriers of using technology integrated in traditional classes. The most prominent barrier is the lack of Information and Communication Technology ( ICT ) skills by the teachers and students and the lack of technical support by the decision makers. Other barriers such as lack of time, access, effective training, and additional workload that ICT integration may cause were also highlighted which teachers may face if they decided to use ICT tools in their classes. Various ICT tools have been integrated into traditional face-to-face classes which work synchronously (time and place dependent $\backslash$ ) and asynchronously (time and place independent) such as wikis,blogs , and discussion boards. This study focuses on the effectiveness of the use of the DBs that provides virtual discussion and said to have achieved better language learning outcomes in other contexts around the world.

Various positive aspects of using DBs have been documented by many researchers around the world. Studies targeted many sectors which use DBs in teaching to support the process of learning, one of them is better achievement. Many studies, old and new, in the Arabic context have implied that integrating DBs into English language classes has impacted student's achievement in a positive way. AL Jarf (2004) study in the Saudi context has shown that using DBs had a positive effect on students' achievement tests. AL Jarf tested two female groups, one experimental which was exposed to online class in addition to an in-class of academic writing, and a control group which only took traditional in-class course .The study showed that the experimental group achieved better in their writing tests as they had an extra opportunity to practice writing.

Alghamdi (2013) examined the possible effect of applying blended online DBs with face-to-face discussion class. The sample of the study were 155 female second-year university students who were enrolled in the Professional Development and Competencies course in a private Saudi university. The participants were divided into two groups .Experimental (65) students and controlled (90) students. To rate their experience, both groups took the same posttest which covered all the topics studied throughout the semester. The study showed better degree of achievement in favor of the experimental group who was exposed to online DBs in addition to face-to-face classes. Furthermore, the study also revealed some "positive effects of blended learning on students' attitudes towards their course" Alghamdi (2013, p.75). Nonetheless, the study revealed some negative sides of using DBs as students would post only if they were promoted by the teacher and provided with a sample answer. This revealed lack of initiative and a lack of motivation to use the Internet for educational purposes rather than amusement.

Adas and Bakir (2013) examined the effect of employing the asynchronous nature of DBs on students' achievement. The study reported findings from research into the benefits of integrating blended learning into traditional methods in developing writing abilities for second and third year undergraduates at a conventional university in Palestine. The investigation involved 60 undergraduate students as the blended course was applied as a new method to one section.30 students, as 
the experimental group and used the traditional face-toface lectures for the other section, another 30 students, as the control group.

The researchers developed an achievement exam (pre and post test) to test the validity of the online course blended with the traditional .Both tests were graded and analyzed in terms of improvement of using a topic sentence, spelling and grammar, punctuation marks and capitalization. The study showed that students in the experimental group performed better than their peers in the control group. In addition, it exhibited evidence of developed writing aspects such as grammar, spelling and punctuations. Through the analysis of students' achievement test results, the study indicated that using technology can create higher achiever students .It concluded that there are two reasons contributed to improvement of writing abilities: first is " the excessive exposure to the online material leads to an effective employment of the language writing abilities" and second is "employing the flexible asynchronous approach" Adas and Bakir (2013,p.263). Adas and Bakir (2013) justified this statement by pointing out that "students enjoyed a lot relating inside instructions and illustrations to outside activities using technology" Adas and Bakir (2013,p263).

Similar statistically significant between the experimental and control groups findings were reported by Sharadgah (2013).The experimental who was exposed to Internet-based programs and face-to-face classes, showed better development in writing performance . The study found that the experimental group showed better development in writing performance and achieved higher in comparison to the control group. .Sharadagh (2013,p.265) cited several reasons behind this development such as the course was " motivational and encouraged students to use the reading-writing strategy and it placed students to in a new learning context". This new learning context has proved to provide low stress environment for students to write in English, in contrast with other studies that reported students frustration over increased stress due to lack of Internet access and computer skills.

The results of these studies are consistent with a more recent study by Alzahrani (2017).Who marked significant differences in students' achievement in favor of the experimental group who was exposed to online discussion forums and in-class discussion.Alzahrani (2017) acknowledged that efficient and effective students 'engagement in DBs environment may enhance their writing skill.The study cited several reasons behind the significant improvement such as social interaction and the collaborative nature in online DBs environment. These studies indicate that the use of DBs incorporated with face-to-face classes is the reason behind getting better achievement, increased collaborative atmosphere, higher order thinking and language development. Alghamdi (2013) Al Jarf (2014), Alharbi (2015) and AlZahrani (2017) found increased level of achievement in the subject of writing particularly of students using DBs as a means of discussion.

These findings have consistently confirmed that integrating DBs had great impact on learners 'achievement and students who actively participated in DBs scored higher than others who did not use DBs.

\section{Participants}

The participants who took part in the current study were undergraduate students. The data were collected from 56 students of department of English, College of Basic Education, and University of Duhok. Participants were males and females undergraduate second stage students and their ages ranged between 19 to 21 years .More than half $(n=33)$ of the participants were females ,while $(n=23)$ were males The students were divided into two main groups, an experimental that involved 28 
students who were taught face-to-face classes and online DBs. The experimental group was enrolled into an online blog that published class materials and provided discussion forums. The Control group included 28 students who were not exposed to the blog or the DBs, but took the same materials in a face-to-face environment. Students in both groups studied Academic writing: from paragraph to essay book by Dorothy $\mathrm{E}$ Zemach \& Lisa A Rumisek (2008).The book was assigned by the department of English as it is believed to take university -level intermediate ability in English as a foreign language into consideration. The book consists of 12 chapters, 5 of them were covered before the midterm exam in 12 weeks ( 2 hours weekly). Topics such as choosing a topic, writing a thesis statement, peer editing, parts of a paragraph, supporting and concluding sentences were taught throughout the course. Students were required to do in -class activities, deliver PowerPoint presentations and submit weekly assignments.

\section{Case Study}

The current study was carried out as a case study. A case study, according to Gall et al (in Duff 2012, p.22) is defined as "the in -depth study of instances of a phenomenon in its natural context and from the perspective of the participants involved in the phenomenon". And since the action research approach applied in this study involves participants in a particular context and social situations in order to improve the rationality and justice of their own social or educational practices, according to Kemmis and McTaggart (1988,p.5), the AR case study is an appropriate approach to be applied

\section{Design of the Course}

The course lasted 12 weeks starting from October 2018 up to the mid of January of 2019. The students were enrolled in a private blog where each had a username and a password to $\log$ in. The blog and discussion were controlled $80 \%$ as (administrator) by the researcher and $20 \%$ by the web designer (super administrator) to detect any technical issue the researcher may encounter. Nineteen subjects covered in the real face-to-face class were posted throughout the course by the researcher. Students could comment and reply to the researcher as well as to each other anytime and anywhere net connection was available. Students were required to participate and interact thoroughly since it was part of their first term assessment criteria. The researcher acted as a facilitator and was in constant contact with the participants through a private messenger group to offer any technical support or clarify any issue related to the posted DB. The researcher did not correct anything posted on the DBs and encouraged students to write freely and not to worry about any grammatical or spelling mistakes. The blog dashboard and a sample of a participant's comment can be seen in figures 1 and 2 below:

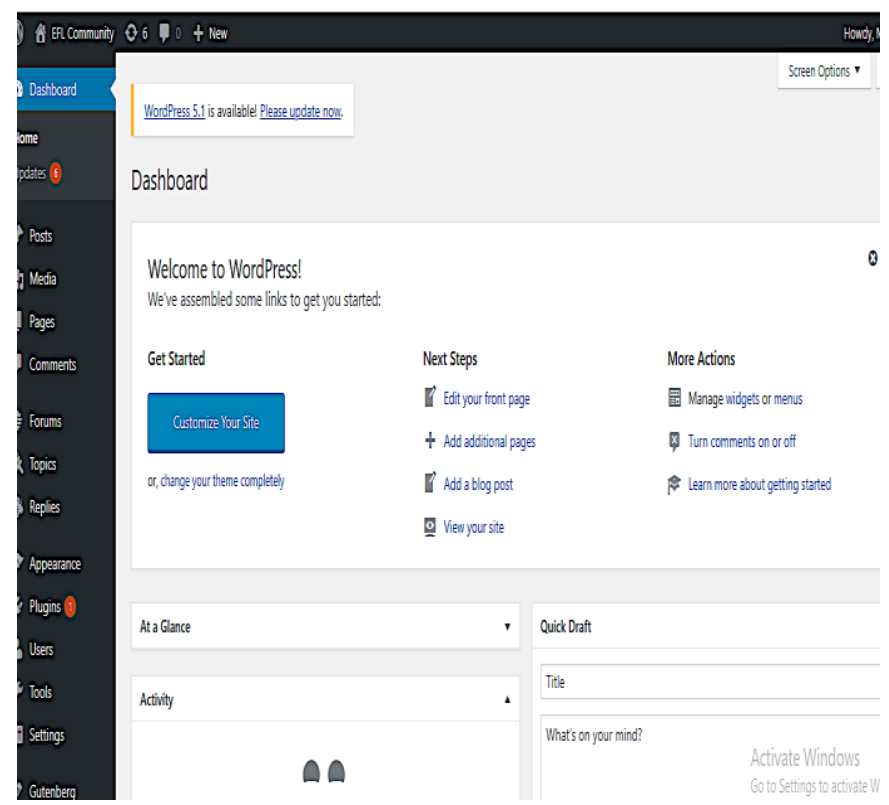

Figure 1: A Sample of the Blog Dashboard 


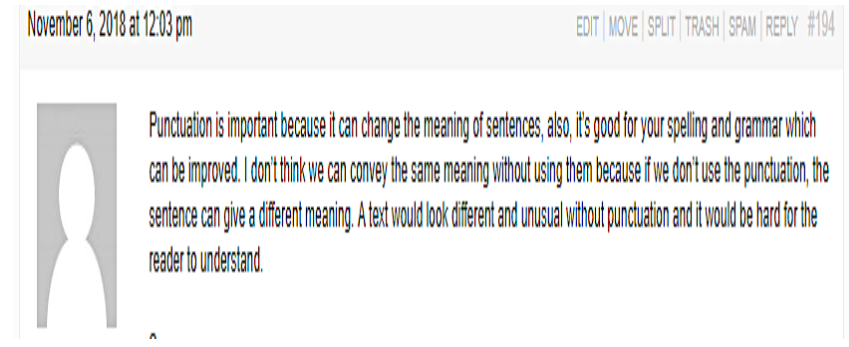

Figure 2. A sample of a participant's comment on the DB

All the topics were covered in a face-to-face context following a course book assigned by the department in a 12-week period of .The 12 -week academic writing was intended to cover all 3 chapters before the mid-term exam in January as seen in the following table:

Table 1

Topics covered in face-to-face class and DBs

\begin{tabular}{lll}
\hline \hline Week & Topics \\
\hline 1 & $\begin{array}{l}\text { Introduction } \\
\text { Overview }\end{array}$ \\
2 & $\begin{array}{l}\text { Pre-writing , getting ready to write } \\
\text { Choosing and narrowing a topic }\end{array}$ \\
& Gathering ideas / brainstorming \\
3 & How to brainstorm \\
& Making a list \\
& Mapping \\
& Free writing \\
4 & Editing ideas \\
& How to edit \\
5 & The structure of a paragraph \\
& What is a paragraph \\
& Understanding a paragraph \\
6 & Paragraph organization \\
& Topic sentences \\
7 & Supporting sentences \\
8 & The topic and the main ides \\
9 & The development of a paragraph \\
& Details \\
& Explanations \\
10 & Examples \\
& Concluding sentences \\
& How to conclude sentences \\
& Peer editing \\
& Why do writers peer edit \\
& Giving constructive suggestions \\
&
\end{tabular}

12 Revision /preparing for the exam assignments /exercises

\section{Data collection}

After the experiment, the experimental and the control groups took the same Mid-term exam. The exam questions were administered and graded by the same teacher. The exam was out of 30 marks and was an important part of the final course assessment. The exam instructions specified paragraph length and components that were taught before such as: topic sentence, supporting and concluding sentences, brainstorming peer editing. All the participant had the exam on the same date and in the same place.

\section{Results}

The results of the test shows a highly significant difference between both groups final achievement test results. As at the .05 level, the experimental group standard deviation is notably higher (4.966) than the control group which is (3.611).Suggesting that the exposure to both traditional and DBs has significantly impacted students' achievement exam results. In addition, the experimental group had higher mean score $(\mathrm{M}=19.07)$ than the control group's mean score $(\mathrm{M}=$ 10.32), Table 6.1 and figure 6.1 show the difference in mean grades of both groups.

Table 2

Students Grades

Grades /30

Group Mean N SD Minimum Maximum Experimen

$\begin{array}{llllll}\text { tal } & 19.07 & 28 & 4.966 & 6 & 27\end{array}$

Control

$10.32 \quad 28 \quad 3.611 \quad 5$

17

Total

14.70

14.70

6.164

5

27 


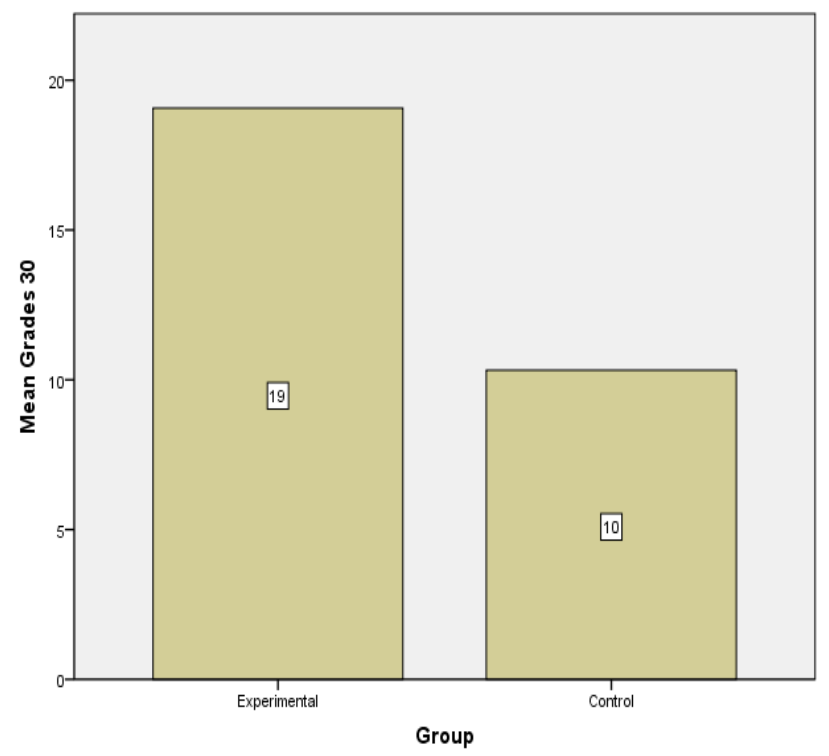

Figure 3: achievement test results of experimental and control groups

\section{Discussion}

The analysis is based upon the results of Mid-term exam which was carried out after a good deal of exposure to the Dbs. This helped the researcher answer the research question:

Does involving students in DBs develop their writing?

These results build on existing evidence that there is a positive correlation between using DBs and developed writing. Based on the results, a statistically significant difference is found between the experimental and control groups in terms of their achievement results in favor of the experimental group. Students who were a part of blended course that implemented DBs to support face-to-face classes have scored higher marks in the Midterm exam than students taught using face-to-face sessions only.

These results are in accordance with (ALJarf 2004, Sharadagh 2013, Alghamdi 2013, Adas and Bakir 2013.Alharbi2015, Alzahrani 2017) results which confirmed better degree of achievement using online DBs with face to face discussion class. Furthermore, the data suggest that DBs are considered a suitable platform to practice writing more. The results are in accordance with (Zhang 2009, Noytim 2010, Nielsen ,2013, Alharbi 2015 and Raba and .Dweikat 2016) which confirmed the role of DBs in developing writing. Based upon this discussion the hypothesis of the study is confirmed.

\section{Conclusion}

The study aimed at examining the effect of DBs implementation in supporting EFL in-class discussion on writing performance. The experiment was pioneering and was conducted for the first time in University of Duhok. Through the utilization of action research approach, the researcher was able to enroll $28 \mathrm{EFL}$ students in online DBs for 12 weeks. The DBs provided the participating students with extra opportunities to practice writing, interact with teacher and peers and extend class discussion asynchronously. Although the participants were unfamiliar enough with using DBs, they showed eagerness and enthusiasm to participate .The study concluded that the DBs and the blog are suitable venues for students to share their perspectives and discuss topics in written forms supported by images, links and videos outside the class. The results of the study provide a strong evidence that the use of DBs can contribute to students' developed writing performance and hence lead to better achievement.

\section{References}

1. Adas, D., \& Bakir, A. (2013). Writing difficulties and new solutions: Blended learning as an approach to improve writing abilities. International Journal of Humanities and Social Science, 3(9), 254-266.

2. Al- Jarf, R. S. (2004). The effects of Web-Based learning on struggling EFL college writers. Foreign Language Annals, 37(1), 49-57. https://doi.org/10.1111/j.19449720.2004.tb021. Retrieved in October 18 2018

3. Alghamdi, A. (2013). Pedagogical Implications of Using Discussion Board to Improve Student Learning in Higher Education. Higher Education Studies, 3(5), 6880. https://doi.org/10.5539/hes.v3n5p68 .Retrieved in March 22nd 2018

4. Alharbi, M. (2015). Effects of Blackboard's Discussion Boards, Blogs and Wikis on Effective Integration and Development of Literacy Skills in EFL Students. English Language Teaching, 8(6), 111- 
132. https:// doi.org/10.5539/elt.v8n6p111 .Retrieved in June 3rd 2018

5. Alzahrani, M. G. (2017). The Effect of Using Online Discussion Forums on Students' Learning. Turkish Online Journal of Educational Technology-TOJET,16(1), 164176. https://doi.org/10.5430/wje.v7n2p1 .Retrieved in March 22nd 2019

6. McTaggart, R., \& Kemmis, S. (Eds.). (1988). The action research planner. Deakin University.

7. Noytim, U. (2010). Weblogs enhancing EFL students' English language learning. Procedia-Social and Behavioral Sciences, 2(2),

$1127-$

1132. https://doi.org/10.1016/j.sbspro.2010.03.159

8. Raba, A. A. A., \& Dweikat, K. A. J.(2016) The influence of English teaching forums on improving eleventh graders 'writing skills in Habla secondary school for girls.

9. Rainey, I. (2000). Action research and the English as a foreign language practitioner: Time to take stock. Educational Action Research, 8(1), 6591.https://doi.org/10.1080/09650790000200112

10. Raman, K., \& Yamat, H. (2014). English teachers' voices on the challenges of the school-based assessment. Frontiers of Language and Teaching, 5(1), 66-74.

11. Ramasubbu, S.The evolution of blended learning 2015,12,December.Huffpost. Retrieved from https://www.huffingtonpost.com/surenramasubbu/the-evolution-of-blendedlearning_b_6666284.html

12. Riasati, M. J., Allahyar, N., \& Tan, K. E. (2012). Technology in language education: Benefits and barriers. Journal of Education and Practice, 3(5), 25-30.

13. Salehi, H., \& Salehi, Z. (2012). Integration of ICT in language teaching: Challenges and barriers. Proceedings of the 3rd International Conference on e-Education, e-Business, eManagement and e-Learning (pp. 215219). Singapore: IACSIT Press

14. Sharadgah, T. A. (2013). Writing in an Internet-Based Environment; Improving EFL Students' Writing Performance through Text-Based Chat. International Journal of Humanities and Social Science, 3(14), 258-266.

15. Singh, H., \& Reed, C. (2001). A white paper: Achieving success with blended learning. Centra software, 1, 1-11.

16. Warni, S. (2016). Implementation of Online portfolios in an Indonesian EFL Writing Class (Doctoral dissertation, University of Sheffield). 